\title{
Being Manageable through Self-efficacy in Heritage Tourism Development
}

\author{
Nurlisa Ginting \\ Faculty of Engineering, \\ University of Sumatera Utara, Indonesia \\ nurlisa@usu.ac.id
}

\begin{abstract}
Being manageable tourism environment allows individuals to carry out their goals with a feeling of selfefficacy. This research aims to observe self-efficacy principle toward supporting heritage tourism in Medan City historic corridor. Mixed-method conducted focuses on four variables, i.e., comfort, safety, accessibility, and confidence. The results indicate that accessibility and confidence significantly contribute in self-efficacy that defines the identity of a place. Meanwhile, it constitutes a threat to self-efficacy when someone feels inconvenience and safe while performing a task in tourism environment.

Keywords: Heritage Tourism; Place Identity; Self-efficacy; Manageable Environment

eISSN 2398-4279 @ 2018. The Authors. Published for AMER ABRA cE-Bs by e-International Publishing House, Ltd., UK. This is an open access article under the CC BY-NC-ND license (http://creativecommons.org/licenses/by-nc-nd/4.0/). Peer-review under responsibility of AMER (Association of Malaysian Environment-Behaviour Researchers), ABRA (Association of Behavioural Researchers on Asians) and cE-Bs (Centre for Environment-Behaviour Studies), Faculty of Architecture, Planning \& Surveying, Universiti Teknologi MARA, Malaysia.

https://doi.org/10.21834/ajqol.v3i11.119
\end{abstract}




\subsection{Introduction}

The awareness of preserving cultural diversity and historic objects encourage heritage tourism development where the knowledge of history and the historical object is the strongest motivation for tourists (Ismagilova et al., 2015). The success of heritage tourism is strongly influenced by the positive perception toward the peculiarity of a place which indicates attraction and satisfaction (Ginting, 2016; Ginting 2017; Wang \& Xu, 2015). A place's peculiarity provides the distinct and different experiences to the people and defines the identity of place. People's satisfaction in a place is closely related to the feeling, emotion, and behavior to affect the place identity.

An identity place is important in developing heritage tourism where it distinguishes a place from others. It builds meaning to environment and attachment to the place (Ujang, 2012). This research aims to observe self-efficacy principle in maintaining place identity toward supporting heritage tourism in Medan City historic corridor.

\subsection{Literature Review}

\section{Self-efficacy and Manageable Environment}

The identity of a place that is well-established and well-preserved causes someone controls their surroundings. A feeling of self-efficacious is maintained through the feeling safe and comfortable. Someone with feeling safe and comfortable will have a positive perception. A comfortable and safe environment will reflect in one's thinking and influence someone in recognizing a place (perception of familiarity). A place which is well-known by people means that it has an identity. The place is worth mentioning on the principle of self-efficacy. This principle is in line with the aspects of "Perception of Familiarity" (Lalli, 1992). It is the result of daily urban experience. Familiarity is assumed as a result of one's actions in a municipal environment which is an expression of the success of one's cognitive orientation.

Self-efficacy is defined as someone's ability to perform a task in a physical and social environment (Belk, 1992). It affects people's behavior through cognitive, motivational, effectiveness, and decision process (Bandura \& Locke, 2003). Regarding with environment, it is maintained if environment facilitates or does not hinder someone's daily life to achieve a positive identification (Twigger-ross and Uzzell, 1996). Winkel (1981) argues it as "a manageable environment." Being manageable tourism environment allows individuals to carry out their goals with a feeling of self-efficacy.

Self-efficacy refers to people's assessment of their ability to perform and achieve expected goals (Bandura, 1997). It is significantly important in a tourism area as it relates to QoL (Firouzmakan and Daneshpour, 2015). People with the respect feeling of self-efficacy will result in greater effort, performance, and satisfaction (Jin et al. 2016). Self-efficacy significantly predicted personal goals (Rampullo, et al., 2015) which refer to intrapersonal factor.

Ben Ami et al. (2014) suggested "Internal-External Efficacy Mode" where externalefficacy will complement self-efficacy's internal focus. External-efficacy indicates individual's belief in availability and quality of required external resources to perform a task. In the current research, researchers focused on internal-efficacy in observing four variables, i.e. comfort, 
safety, accessibility, and confidence to reveal respondent's perception toward self-efficacy in supporting tourism. The variables are assessed through the provision of public facilities (see Table.1).

Table 1. Respondents' Perception about Self-efficacy Principle in Research Area

\begin{tabular}{|c|c|c|c|}
\hline \multirow[b]{2}{*}{ Comfort } & \multicolumn{2}{|c|}{ Self-efficacy Principle } & \multirow[b]{2}{*}{ Confidence } \\
\hline & Safety & Accessibility & \\
\hline $\begin{array}{l}\text { - The existence of } \\
\text { landscape } \\
\text { - Provision of } \\
\text { Dustbins } \\
\text { - Provision of Public } \\
\text { Toilet } \\
\text { - Provision of Sitting } \\
\text { facility }\end{array}$ & $\begin{array}{l}\text { - Quality of } \\
\text { pedestrian path }\end{array}$ & $\begin{array}{l}\text { - Sufficient number of } \\
\text { public transportation } \\
\text { - Provision of parking } \\
\text { facility }\end{array}$ & $\begin{array}{l}\text { - Provision of signage } \\
\text { - Provision of } \\
\text { information center }\end{array}$ \\
\hline
\end{tabular}

\subsection{Methodology}

The research area is a historic corridor in the center of Medan city and extends from Brigjend Katamso Street, Pemuda Street, Ahmad Yani Street to Balai Kota Street. These streets already existed since the early period of Medan city. Through history, the unity of these streets with the surrounding environment has developed to be a historical corridor (JansenVerbeke in Ashworth and Page, 2011). The existence is exceedingly important as it connects Medan city to the main port, Belawan.

Along with time, the corridor was divided into three parts (Fig.1) where the first part, Merdeka Square, constitutes the center of Netherland authority. It is surrounded by the colonial constitutional and commercial buildings with Art Deco and Renaissance architectural style. The second part is the center of Malay authority where Maimoon Palace as the landmark of Malay culture in Medan took place. Meanwhile, a commercial area constituted by Chinese culture known as Kesawan Area is between the other authorities.

The corridor is chosen due to the historical buildings in Medan city, from the NetherlandIndies colonial inheritance, Chinese's Tjong A Fie House, to Malay's Maimoon Palace. The historical buildings are a primary element of tourism (Jansen-Verbeke in Ashworth and Page, 2011) that distinguishes the corridor from other places and supports the heritage tourism. Its existence indicates the success of tourism in an area (Ismagilova et al., 2015). Moreover, the areas have distinct historical value including culture, activities, and physical elements that reflect their authority in the colonial period. The distinction in the areas creates a unique image of Medan City.

This research was conducted in 2012 by employing mixed-method to observe respondents' perception toward efficacy in the area which focuses on four variables, i.e., comfort, safety, accessibility, and confidence (Tabel 1). It is based on various sources of facts and data collected through the triangulation method because the relationship between humans and the environment is influenced by many factors that are investigated simultaneously whether through qualitative data or quantitative data. In this research, the 
qualitative method was conducted through direct observation to the research area and depth interview while 360 questionnaires distributed in employing the quantitative method. This method resembles the investigations undertaken by Liu et al. (2005), McKercher et al. (2005), and Twigger-Ross and Uzzell (1996) using the qualitative method as well as quantitative method.

In this research, the key respondents who participated in-depth interview $(n=9)$ were among the tourism enthusiasts such as the festive regulator (Head of INCCA North Sumatra); tour operator (Head of ASITA North Sumatera); Forum Hotel Manager; owner of a heritage building i.e., Tjong A Fie House and Maimoon Palace; Government officers i.e., North Sumatera Tourism Personnel and North Sumatera Cultural Figures. Meanwhile, the questionnaires were distributed to the selected respondents $(n=360)$ equally $(50 \%$ local people and $50 \%$ tourists). The current research limits its observation on the external-efficacy because the perception towards the efficacy was conducted based on the environmental condition and external resources that lie outside a person, such as facilities and landscape quality in the area. The four variables of self-efficacy were assessed through nine indicators (Tabel 1) which are the main resources in Medan historic corridor. However, the indicators could be varying in different locations of the research area depending on the type of the tourism or the geographical situation of the place.

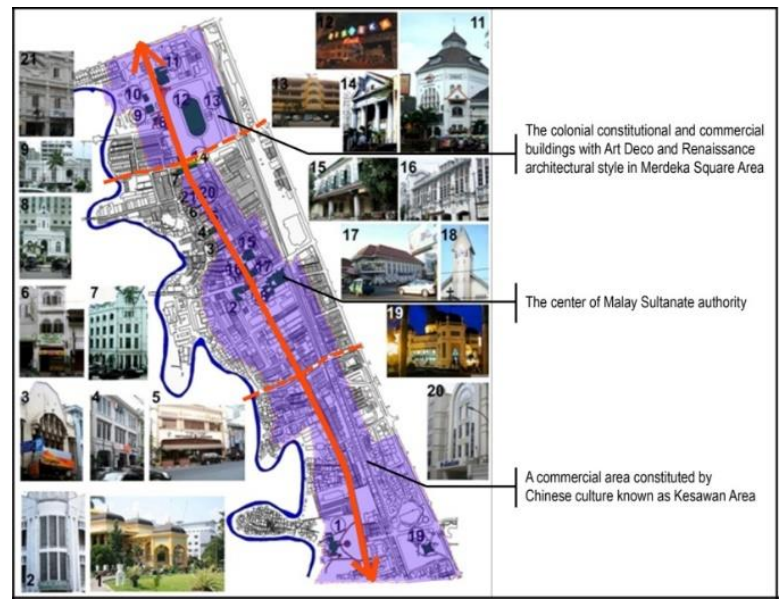

Figure 1: Research Area

\subsection{Findings and Discussions}

Each area is represented by 120 respondents consisted of local people (60) and tourist (60). The majority of respondents are $25-49$ years old $(56 \%)$, followed by $(28 \%)$ respondents are between $50-64$ years old where almost of $55 \%$ of them is male. The foreign tourist from Europe/America is dominated by Germany, Netherland, and America, while Malaysia and Singapore are more dominant in Maimoon Area and Merdeka Square area. The respondents 
are people with higher education and high income where they usually traveled with their friends $(75 \%)$.

It is possible to see that there are differences between local people and tourists in their perception of self-efficacy (Tabel 1). Respondents argue that accessibility and confidence significantly contribute in self-efficacy that defines the identity of a place (Table 1).

Table 1. Respondents' Perception about Self-efficacy Principle in Research Area

\begin{tabular}{|c|c|c|c|c|c|c|c|c|c|c|c|c|}
\hline \multirow{3}{*}{ Facts } & \multicolumn{4}{|c|}{ Maimoon Area } & \multicolumn{4}{|c|}{ Kesawan Area } & \multicolumn{4}{|c|}{ Merdeka Square Area } \\
\hline & \multirow{2}{*}{$\begin{array}{l}\text { Local } \\
\text { people } \\
\text { Min }\end{array}$} & \multirow[b]{2}{*}{ Stev } & \multicolumn{2}{|c|}{ Tourists } & \multicolumn{2}{|c|}{$\begin{array}{l}\text { Local } \\
\text { people }\end{array}$} & \multicolumn{2}{|c|}{ Tourists } & \multicolumn{2}{|c|}{$\begin{array}{l}\text { Local } \\
\text { people }\end{array}$} & \multicolumn{2}{|c|}{ Tourists } \\
\hline & & & Min & Stev & Min & Stev & Min & Stev & Min & Stev & Min & Stev \\
\hline Landscapes & 3.37 & 0.69 & 3.47 & 0.93 & 3.57 & 0.85 & 3.38 & 0.78 & 3.53 & 0.68 & 3.67 & 0.68 \\
\hline Bins & 2.82 & 0.95 & 2.48 & 1.02 & 2.72 & 0.87 & 2.90 & 0.88 & 2.77 & 0.85 & 3.05 & 1.00 \\
\hline Signage & 3.22 & 0.76 & 3.05 & 0.81 & 3.27 & 0.78 & 2.85 & 0.71 & 3.20 & 0.78 & 3.00 & 0.86 \\
\hline Public toilet & 2.73 & 0.82 & 2.80 & 0.92 & 2.68 & 0.89 & 2.87 & 0.93 & 2.42 & 0.77 & 2.80 & 0.92 \\
\hline Sitting Area & 2.83 & 0.78 & 2.28 & 0.88 & 2.88 & 0.88 & 2.95 & 0.98 & 2.77 & 0.79 & 3.10 & 0.75 \\
\hline $\begin{array}{l}\text { Information } \\
\text { center }\end{array}$ & 3.17 & 0.87 & 3.12 & 0.87 & 3.15 & 0.76 & 3.22 & 0.76 & 2.97 & 0.64 & 3.20 & 0.82 \\
\hline Parking & 3.12 & 0.87 & 3.03 & 0.94 & 3.05 & 0.85 & 3.15 & 1.02 & 3.23 & 0.79 & 3.40 & 0.67 \\
\hline $\begin{array}{l}\text { Pedestrian } \\
\text { path }\end{array}$ & 3.30 & 0.98 & 3.17 & 1.01 & 3.20 & 0.90 & 3.08 & 1.06 & 3.12 & 0.94 & 3.50 & 0.81 \\
\hline $\begin{array}{l}\text { Public } \\
\text { transportation }\end{array}$ & 3.35 & 0.82 & 3.18 & 0.87 & 3.22 & 0.92 & 3.12 & 0.83 & 3.28 & 0.83 & 3.48 & 0.83 \\
\hline $\begin{array}{l}\text { Value format: } \\
1=\text { strongly } \\
\text { disagree, } 5= \\
\text { strongly } \\
\text { agree }\end{array}$ & 3.10 & 0.83 & 2.95 & 0.91 & 3.08 & 0.85 & 3.05 & 0.88 & 3.03 & 0.78 & 3.24 & 0.82 \\
\hline
\end{tabular}

\subsection{Comfort}

In maintaining self-efficacy, comfort must be fulfilled to allows someone to perform in the physical environment. Since someone feels comfortable in his or her surroundings, s/he will easily perform certain goals (Twigger-ross and Uzzell, 1996). Comfort will generate satisfaction towards the place (Ujang, 2012) while uncomfortable feeling will distract the selfefficacious and cause negative effects on tourism. In this research, the comfort in the corridor is affected by surrounding physical condition, including landscape, provision of dustbins, public toilets, and sitting area as well.

A landscape should be a space for people to facilitate their daily activities. Dixon and Dürrheim (2004) seen place identity as a social process that contributes the attachment to the physical environment. This attachment will affect the feeling of comfortable of an area (Carmona \& Tiesdell, 2007) that is important in fulfilling needs and goals (Ujang, 2012). The result showed that the respondents have positive perceptions of the landscapes in the corridor (Table 1). The existence of trees in the area and the uniqueness of landscape design affected the perception of comfort.

In contrary, provision of pedestrian facilities includes dustbins, public toilets, and sitting area received negative assessments from the respondents whereas it will influence a pedestrian's sense of comfort. There is no a sufficient number of good dustbins and public 
toilet so they can not maintain the cleanliness. It creates the feeling uncomfortable among respondents. This is supported by the depth interview with the tourism stakeholder:

"I feel uncomfortable here due to few number of dustbins. As you can see, we can rarely find it that many trash is thrown away" (Key Respondents: Forum Manager Hotel)

"It does not seem to answer anymore. There is no public toilet except in Mosques or restaurants, but its existence is limited for public using" (Key Respondents: Culture Figure/Academics)

This causes negative effects towards QoL in the area (Firouzmakan and Daneshpour, 2015) whereas the provision of public toilet contributes to a comfortable environment (Ja'afar et al., 2012). Based on the respondents' perception toward pedestrian facilities, required more improvement of its provision and condition to create a comfortable feeling. Moreover, the comfortable feeling is influenced by the provision of sitting area. The respondents also feel uncomfortable with the sitting area (Table 1) as they can hardly find a place to relax and interact each other, whereas sitting area would motivate social interaction and communication as human needs to control their surroundings (Belk, 1992). The opportunity to sit and relax will make the visitors feel comfortable and generate the QoL in the area (Ja'afar et al., 2012).

\subsection{Safety}

Safety is important to achieve visitors' comfort and satisfaction. The lack of safety will damage the QoL in the area (Firouzmakan dan Daneshpour, 2015). In heritage tourism area, it becomes one of the services that must be provided (Butnaru and Miller, 2012) for the visitors while enjoying historical objects in the area. Its existence can create someone's efficacy in performing a task.

In developing heritage tourism, pedestrians' safety should be prioritized so they can safely and comfortably enjoy the surrounding area. Hence, it must be well-planned to connect several activities. Unfortunately, the pedestrian path in research area was not well-planned and not integrated to the parking and bus stop. Thus, they must walk through vehicle ways to access heritage objects in the area.

Furthermore, the quality of pedestrian path in the area is very bad due to the poor pavements and the disconnected path. It makes the visitors not feel safe to walk there. The off-street parking and street vendors along major roads illegally used the pedestrian space (Fig.2). This situation causes a threat, fear, and danger for the visitors that affected their perceptions of the place identity (Ujang, 2012). It is strengthened that the respondents gave low assessments about the pedestrian paths (Tabel 1). This is also supported by the depth interview with the heritage building owner:

"Let's take a look at the pedestrian path! It is so uncomfortable and disconnected whereas it should be able to support tourism. Not only the tourists but also the local people need walk safely." (Key respondent:

The owner of Tjong A Fie House)

The results show that the research area is not able to create an identity as a safe place due to the lack of pedestrian facility. The environmental qualities which facilitate walking indicate a pedestrian's sense of comfort (Zakaria and Ujang, 2015). A walkable place allows someone to experience the area and enhance people efficacy in tourism activity. 


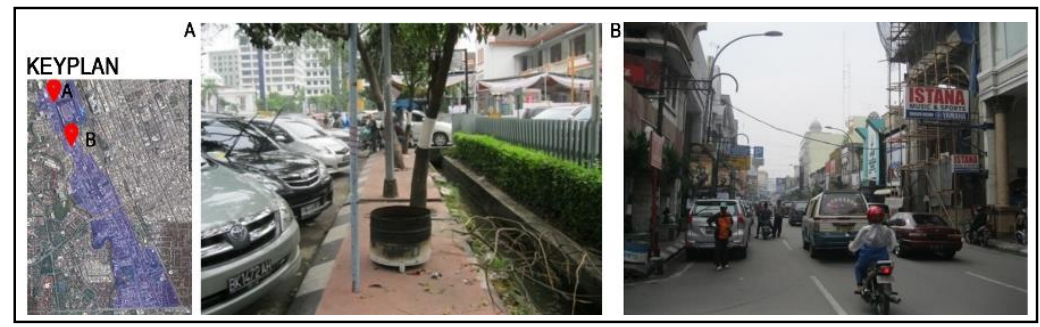

Figure 2. Pedestrian Path in Research Area

\subsection{Accessibility}

Embedding efficacy in a tourism area requires good accessibility as well. The accessibility helps people in orientating and perform a task appropriately (Twigger-Ross and Uzzel, 1996). It becomes significant in heritage tourism area, where the tourists have the intention to access many historical objects. A place is accessible when an equal opportunity for everybody to use the public spaces is existed (Zakaria and Ujang, 2015). The easier access, the higher a person's interest to visit a place. A normal person can be disabled if the accessibility is not provided (Zakaria and Ujang, 2015). In this case, the accessibility was assessed through the public transportation, connected pedestrian paths, and parking facility.

One's ability to orient is also closely related to the public transport system. When public transportation is easily found in heritage tourism area, it shows a good accessibility. The results of the analysis show that respondents gave proper assessment toward the sufficient of public transportation (Table 1). However, they are still disappointed due to the crowded traffic flow and connectivity of pedestrian path.

Moreover, though there is adequate parking space (Table 1), respondents argue that the integration between parking space and street must be well planned. Street with a large number of frontages taken up by parking causes pedestrian access to buildings more difficult (Fig.3). The existence of parking space enables visitors to organize and perform various activities elsewhere (Bandura, 1995). It should facilitate the street's users to access a place and work effectively (Belk, 1992). Moreover, the street networks must be well connected with the proper pedestrian path to the varied destination to encourage walking activity. A wellplanned street network has streets that well-linked to other modes of transportation (Southworth, 2005).

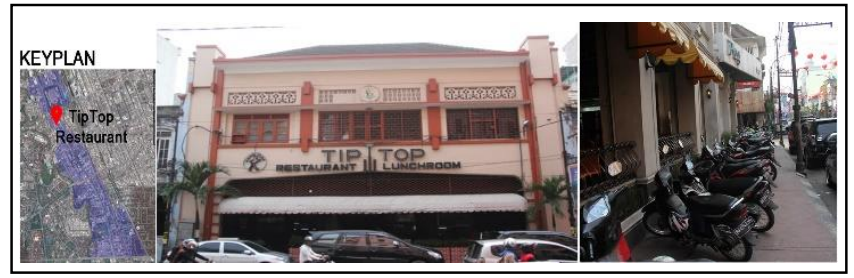

Figure 3. The Off-parking Street in Front of Tip Top Restaurant 


\subsection{Confidence}

Confidence exceedingly exists when someone believes that someone can carry out the activities and control the surroundings. It is conceived as "a manageable environment" (Twigger-Ross dan Uzzell, 1996; Winkel, 1981). In the same time, it is also required for human psychological well-being (Bandura, 1997). If the environment cannot provide confidence to the users, it can constitute a threat to self-efficacy (Twigger-Ross dan Uzzell, 1996).

The existence of unique and distinct landscapes in the research area contributes to visitors' confidence to orientate. It determines their positions and destination in travel planning. The result indicates that respondents have positive perceptions of the landscapes (Table 1) due to the existence of historical objects that indicates the image of a place.

Furthermore, the availability of information center in maintaining self-efficacy must be provided in perceiving "manageable environment." People must be able to access the current and reliable information about travel planning. From Table 1, it sees that people hardly find the information center in the research area. No tourist information can be accessed the hotel they will stay through the website or leaflet. This is supported by the interview with the key respondents:

"We can hardly get information due to the absence of information center, even on the website provided" (Key respondent: Head of North Sumatera INCCA (Indonesian Congress and Convention Association))

Moreover, the existence of signage also creates the unconfident feeling in the research area (Table 1). Entertainment boards are more dominated the signage (Fig.4). Whist helps people to know their destination and create a legible environment. It is supported by depth interview:

"Too much entertainment boards in Medan City promoting non-tourism products. Hence, I was disturbed due to no promoting tourism board, no directions, and no travel arrangements, as well as the entertainment boards, covered the distinct heritage buildings" (Key Respondents: Tourism Figure)

When environment facilitates a person's daily lifestyle in a social-physical environment, it will build significant symbolic values. A manageable environment reveals confident feeling among tourists so they can perform a task efficiently. They are also able to enjoy their visit while observing the unique historical objects.

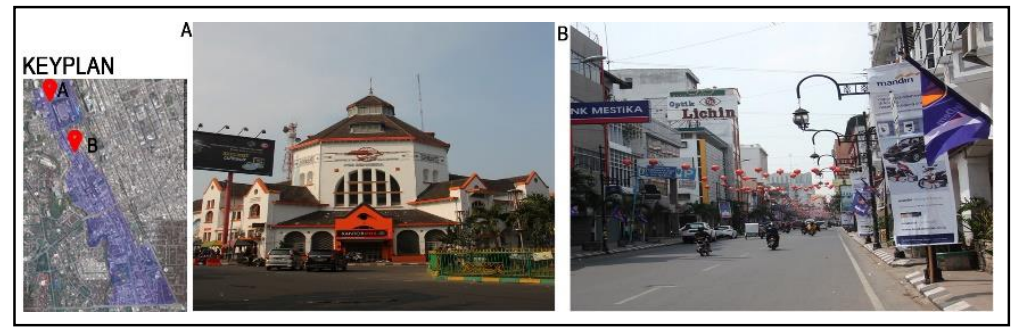

Figure 4. Entertainment Boards Dominated The Signage

\subsection{Conclusion}

People's perception of place identity significantly contributes to creating attraction and 
satisfaction and affect the success of heritage tourism. A well-established and well-preserved place Identity leads local people and tourists visiting a place to control their lives. As a need, humans want a comfortable atmosphere and a sense of security in their surroundings. Over the years, various efforts have been made to prioritize the identity of a place. The relationship between a person and his surroundings is closely related to his experience. Through such relationships, an environment has a significant symbolic value about one's social, emotional, and action (Lalli, 1992).

This current research conducted, implemented in the context of social psychology. It examines self-efficacy principle, one of place identity principles, through the perception of local people and tourists alike. One approach revealing self-efficacy is how an environment provide external resources human need in performing their goals (external-efficacy). The environment fulfilling people's necessity, such for the provision of public facilities and services, directly will drive good QoL in a place.

Four indicators namely comfort, safety, accessibility, and confidence were assessed to get positive and negative perceptions towards self-efficacy aspect in the study area. The result shows that accessibility and confidence contribute in embedding positive perception of respondents due to the sufficient number of public transportation and existence of unique and distinct landscapes, respectively. However, The poor facilities of pedestrians require further considering the need for comfort and safety. Safe and pleasant pedestrian environment could influence tourists' choice to experience the tourism objects in the area. For further research, the author highly recommended further research of self-efficacy principle in another type of tourism.

\section{Acknowledgement}

The author gratefully acknowledges to the University of Sumatera Utara and the research team for their support.

\section{References}

Ashworth, G., \& Page, S. J. (2011). Urban tourism research: Recent progress and current paradoxes. Tourism Management, 32(1), 1-15.

Bandura, A. (1995). Exercise of personal and collective efficacy in changing societies. In Bandura, A. (Eds,), Selfefficacy in changing societies. Cambridge: Cambridge University Press.

Bandura, A. (1997). Self-efficacy: The exercise of control. In Lunenburg, F. C. (2011). Self-efficacy in the workplace: implications for motivation and performance. International Journal of Management, Business, and Administration, 14(1), 1-6.

Belk, R. W. (1992). Attachment to possessions. In S. M. Low, \& I. Altman (Eds.), Place attachment: Human behavior and environment (pp. 37-62). New York: Plenum Press.

Ben-Ami, M., Hornik, J., Eden, D., \& Kaplan, O. (2014). Boosting consumers' self-efficacy by repositioning the self. European Journal of Marketing, 48, 1914-1938. 
Butnaru, G.I., Miller, A. (2012). Conceptual approach on quality and theory of tourism services. Procedia Economics and Finance, 3, 375-380

Carmona, M. and Tiesdale, S. (2007). Urban Dessign Reader. London: Architectural Pres.

Dixon, J., \& Durrheim, K. (2004). Dislocating identity: Desegregation and the transformation of place. Journal of Environmental Psychology, 24(4), 455-473.

Firouzmakan, S., \& Daneshpour, S. A. (2015). Promotion Quality of Life by Increasing Place Attachment in Public Places. Procedia-Social and Behavioral Sciences, 201, 418-428.

Ginting, Nurlisa. (2016). How Self-Efficacy Enhance Heritage Tourism in Medan Historical Corridor, Indonesia. Procedia - Social and Behavioral Sciences, 234,193 - 200

Ginting, N., Nasution, A. D., Rahman, N. V. (2017). More Attractive More Identified: Distinctiveness in Embedding Place Identity. Procedia Environmental Sciences, 37, 408 - 419

Ismagilova, G., Safiullin, L., \& Gafurov, I. (2015). Using Historical Heritage as a Factor in Tourism Development. Procedia-Social and Behavioral Sciences, 188, 157-162.

Ja'afar, N.H., Sulaiman, A.B., Shamsuddin, S. (2012). The contribution of landscape features on traditional streets in Malaysia. Procedia-Social and Behavioural Sciences, 50, 643-656.

Jin, Xin et al. (2016). How do Worry, Self-efficacy, and Coping Interact? Examining Chinese tourists to Australia. Journal of China Tourism Research. DOI: 10.1080/19388160.2016.1251868

Lalli, M. (1992). Urban-related Identity: Theory. Measurement, and Ampirical Findings. Journal of Environmental Psychology,. 12:285-303.

Liu, J. H. and Hilton, D. J. (2005). How the Past Weighs on the Present: Social representations oh History and Their Role in Identity Politics. British Journal of Social Psychology, 44, 537-556

McKercher, B and Du Cros, H. (2005). Testing A Cultural Tourism Typology. The International Journal of Tourism Research. 5: 45-58.

Rampullo, A., Licciardello, O., Castiglione, C. (2015). Intrapersonal Factors Effects on Professional Orientation and Environmental Representations. Procedia - Social and Behavioral Sciences, 205, 422-428.

Southworth, M. (2005). 'Designing the Walkable City. Journal of Urban Planning and Development' 131: 246-257.

Twigger-Ross, C. L., \& Uzzell, D. L. (1996). Place and identity processes. Journal of environmental psychology, 16(3), 205-220.

Ujang, Norsidah. (2012). Place attachment and continuity of urban place identity. Procedia-Social and Behavioural Sciences, 49, 156-167

Wang, S., \& Xu, H. (2015). Influence of place-based senses of distinctiveness, continuity, self-esteem and selfefficacy on residents' attitudes toward tourism. Tourism Management, 47, 241-250.

Winkel. (1981). The Perception of Neigbourhood Change. In J Harvey Ed. Cognition and Social Behaviour \& the Environment. New York: Enbaum.

Zakaria, J and Ujang,N. (2015). Comfort of Walking in the City Center of Kuala Lumpur. Procedia - Social and Behavioral Sciences . 170. $642-652$ 